\title{
Knowledge, attitude and practice towards tuberculosis in Gambia: a nation-wide cross-sectional survey
}

\author{
Adedapo Olufemi Bashorun ${ }^{{ }^{*}}$ (D), Christopher Linda ${ }^{1 \dagger}$, Semeeh Omoleke ${ }^{1 \dagger}$, Lindsay Kendall', Simon D. Donkor ${ }^{1}$, \\ Ma-Ansu Kinteh', Baba Danso ', Lamin Leigh', Sheriff Kandeh', Umberto D'Alessandro ${ }^{1}$ and \\ Ifedayo Morayo O. Adetifa, ${ }^{1,2}$
}

\begin{abstract}
Background: Early diagnosis and treatment of tuberculosis (TB) are the mainstay of global and national TB control efforts. However, the gap between expected and reported cases persists for various reasons attributable to the TB services and care-seeking sides of the TB care cascade. Understanding individual and collective perspectives of knowledge, attitudes, beliefs and other social circumstances around TB can inform an evidence-based approach in engaging communities and enhance their participation in TB case detection and treatment.

Methods: The study was conducted during the Gambian survey of TB prevalence. This was a nationwide crosssectional multistage cluster survey with 43,100 participants aged $\geq 15$ years in 80 clusters. The study sample, a random selection of $10 \%$ of the survey population within each cluster responded to a semi-structured questionnaire administered by trained fieldworkers to assess the knowledge, attitudes and practice of the participants towards TB. Overall knowledge, attitude and practice scores were dichotomised using the computed mean scores and analysed using descriptive, univariable and multivariable logistic regression.

Results: All targeted participants (4309) were interviewed. Majority were females 2553 (59.2\%), married 2614 (60.7\%), had some form of education 2457 (57\%), and were unemployed 2368 (55\%). Although 3617 (83.9\%) of the participants had heard about TB, only 2883 (66.9\%) were considered to have good knowledge of TB. Overall 3320 (77\%) had unfavourable attitudes towards TB, including 1896 (44\%) who indicated a preference for staying away from persons with TB rather than helping them. However, 3607(83.7\%) appeared to have the appropriate healthseeking behaviours with regard to TB as 4157 (96.5\%) of them were willing to go to the health facility if they had symptoms suggestive of TB.

Conclusions: About 3 in 10 Gambians had poor knowledge on TB, and significant stigma towards TB and persons with TB persists. Interventions to improve TB knowledge and address stigma are required as part of efforts to reduce the burden of undiagnosed TB in the country.
\end{abstract}

Keywords: Tuberculosis, Knowledge, Attitude, Practice, Stigma, Prevalence survey, Africa

\footnotetext{
* Correspondence: adbashorun@mrc.gm

${ }^{+}$Christopher Linda and Semeeh Omoleke contributed equally to this work. 'Disease Control and Elimination Theme, Medical Research Council Unit The Gambia at London School of Hygiene and Tropical Medicine, P.O. Box 273, Banjul, The Gambia

Full list of author information is available at the end of the article
}

(c) The Author(s). 2020 Open Access This article is licensed under a Creative Commons Attribution 4.0 International License, which permits use, sharing, adaptation, distribution and reproduction in any medium or format, as long as you give appropriate credit to the original author(s) and the source, provide a link to the Creative Commons licence, and indicate if changes were made. The images or other third party material in this article are included in the article's Creative Commons licence, unless indicated otherwise in a credit line to the material. If material is not included in the article's Creative Commons licence and your intended use is not permitted by statutory regulation or exceeds the permitted use, you will need to obtain permission directly from the copyright holder. To view a copy of this licence, visit http://creativecommons.org/licenses/by/4.0/ The Creative Commons Public Domain Dedication waiver (http://creativecommons.org/publicdomain/zero/1.0/) applies to the data made available in this article, unless otherwise stated in a credit line to the data. 


\section{Background}

With the implementation of the End TB strategy, the global incidence of tuberculosis (TB) fell at $~ 2 \%$ annually from 2000 to 2018 , but this decline was too slow to attain global TB control targets - 20\% reduction in global incidence between 2015 and 2018, 80\% reduction in TB incidence and $90 \%$ reduction in TB deaths by 2030 in comparison to 2015 [1, 2]. This situation is replicated in The Gambia where the decline in TB incidence has stagnated - 175 per 100,000 population in 2012 [3] to 174 per 100,000 population in 2018 [1]. Worldwide, TB continues to be responsible for the most deaths attributable to a single infectious disease [1].

Detecting and treating primary and secondary $\mathrm{TB}$ cases with the aim of increasing TB treatment coverage is a major component of the End TB Strategy [1]. However, despite ongoing efforts, there remains a significant gap between the number of notified and incident cases. This is reflected in the significant burden of undiagnosed TB cases found in the community during TB prevalence surveys in The Gambia [3] and elsewhere in Africa [4-10]. Addressing the gap in TB case finding requires an understanding of who is missed and how to decrease delays in TB case detection [11]. Lack of high quality TB services may be one factor [11]. However, delay in people seeking healthcare, despite adequate service provision, due to a failure to recognize the significance of a given symptom complex may be another important element $[11,12]$. Delays in case detection, notification and treatment are known to be associated with poor perception of and confidence in available health care facilities and staff; stigma and poor knowledge of TB including misconceptions regarding transmission and prevention [2, 13-20]. Care seeking behaviour has been shown to be influenced by knowledge about the symptoms and signs of TB [20-23]. Thus, interventions to address these societal or community-level factors are required to improve or contribute to $\mathrm{TB}$ case detection and treatment success. It is for this reason that effective community engagement including advocacy, communication and social mobilisation activities (ACSM) is an essential component of the 2nd pillar of the World Health Organisation's End TB strategy [1].

In The Gambia, the National Leprosy and Tuberculosis Control Programme's (NLTP) strategic plan includes ACSM which it implements principally to sensitise communities to enhance their participation in TB case finding [24]. A better understanding of communitylevel knowledge, attitude and practices (KAP) related to TB can help the NLTP design and implement evidencedriven ACSM activities as part of its mandate to control TB in The Gambia. The evidence-driven ACSM activities are key part of NLTP's acceleration of quality health services and universal coverage policy [25]. Therefore, as part of the first TB prevalence survey in the Gambia, [3] we assessed the knowledge, attitude and practice (KAP) related to $\mathrm{TB}$ in a nationally representative population.

\section{Methods \\ Study design}

This was a cross-sectional survey conducted alongside the Gambian Survey of TB Prevalence (GAMSTEP) the parent study that was a nationwide multistage cluster survey conducted in 80 clusters allocated to regions of the country in proportion to population size [3].

\section{Study setting}

The study was conducted from 2011 to 2013 in The Gambia which is the smallest mainland country in Africa with a population of about 1.9 million [26] and has had an average rate of growth of $2.8 \%$ per year over the last decade [27]. It is one of the most densely populated countries in Africa with an estimate of 177 people per square kilometre [27].

\section{Study participants}

Eligible participants were those $\geq 15$ years, resident in each cluster, spent at least one night in the household in the preceding 4 weeks and/or visitors who had arrived in the household 4 weeks or more before the survey [3]. On each survey day, the team chooses a starting number by taking the first number of the serial number on any random Gambian dalasis (currency) note after which all the tenth survey participants starting from this number were then selected for the KAP survey.

\section{Study variables}

The main outcomes of interest were knowledge, attitude and practice of study participants while the exposure variables were areas of residence. Our general predictors were age, sex, marital status, occupational status and employment status.

\section{Data sources, measurement and analysis}

Participants were interviewed in their own language by trained field workers using a pre-tested 29-item questionnaire (see additional file 1). The questionnaire was developed for this study based on the previous work in the country which identified gaps in attitude and knowledge $[16,28]$ and adapted content from a sister WHOassited national TB prevalence survey in Ethiopia [4] and the WHO TB prevalence survey handbook [29]. Prior to the main study, the questionnaire was piloted and standardised as well as training on key words translations in the several spoken Gambian languages, so as to ensure consistency. And during the conduct of the study, there were several refresher training sessions. 
We recorded responses to questions about sociodemographic characteristics, knowledge about TB, health care seeking behaviour, and stigma towards TB.

All data were double entered into a MySQL version 5.6.19 (Oracle, Redwood Shores, USA) relational database. Data analyses was done using Stata version 12.0 (Stata Corp., College Station, USA).

Overall, TB knowledge was assessed by 7 main questions about $\mathrm{TB}$ symptoms, $\mathrm{TB}$ transmission, ways to avoid getting $\mathrm{TB}$, risk acquiring $\mathrm{TB}$, whether $\mathrm{TB}$ can be cured and how, and cost of TB treatment within the country. Some of these questions had multiple answer options, thus the correct options (12 items) were used in the classification of the knowledge level. A score of one was given for each correct response and zero was given to incorrect and 'do not know' responses. Participants who had a score equal to and above the mean score of the study population were considered to have 'good' knowledge of $\mathrm{TB}$ and those with below the mean score were considered to have 'poor' knowledge of TB.

Similarly, we assessed attitude to TB via 4 questions: understanding that $\mathrm{TB}$ can affect anyone, a favourable reaction if found to have $\mathrm{TB}$, who they will be willing to talk to if found to have TB, and desire to help people with TB. Using the mean score, participants were categorised as having 'favourable' or 'unfavourable' attitudes.

Practice or health seeking-behaviour was assessed with 2 questions: willingness to go to the health facility, and plan for timely visit to a health facility if respondents thought they had TB symptoms. Participants were considered to have 'good' practice or 'poor' practice using a mean score as a cut-off.

Table 1 Socio-demographic characteristics of the respondents

\begin{tabular}{|c|c|c|c|}
\hline Characteristic & Rural - 2558 N (\%) & Urban - $1751 N(\%)$ & Total $-4309 N(\%)$ \\
\hline \multicolumn{4}{|l|}{ Sex } \\
\hline Female & $1568(61.3)$ & $985(56.2)$ & $2553(59.2)$ \\
\hline Male & $990(38.7)$ & $766(43.8)$ & $1756(40.8)$ \\
\hline \multicolumn{4}{|l|}{ Age distribution } \\
\hline $15-34$ years & $1568(61.3)$ & $1167(66.7)$ & $2735(63.5)$ \\
\hline $35-64$ years & $817(31.9)$ & $534(30.5)$ & $1351(31.4)$ \\
\hline $65+$ years & $173(6.8)$ & $50(2.8)$ & $223(5.1)$ \\
\hline \multicolumn{4}{|l|}{ Marital status } \\
\hline Married & $1708(66.7)$ & $906(51.7)$ & $2614(60.7)$ \\
\hline Single & $738(28.9)$ & $758(43.3)$ & $1496(34.7)$ \\
\hline Widow/widower & $91(3.6)$ & $30(1.7)$ & $148(3.4)$ \\
\hline Separated/Divorced & $21(0.8)$ & $57(3.3)$ & $51(1.2)$ \\
\hline \multicolumn{4}{|l|}{ Educational status } \\
\hline Illiterate & $1315(51.4)$ & $537(30.7)$ & $1852(43.0)$ \\
\hline Primary/Incomplete Secondary school & $462(18.1)$ & $512(29.2)$ & $974(22.6)$ \\
\hline Read English/Arabic only & $513(20.0)$ & $264(15.1)$ & $777(18.0)$ \\
\hline Complete Secondary school and above & $268(10.5)$ & $438(25.0)$ & $706(16.4)$ \\
\hline \multicolumn{4}{|l|}{ Occupational status } \\
\hline Unemployed & $1416(55.3)$ & $952(54.4)$ & $2368(55.0)$ \\
\hline Employed & $1140(44.6)$ & $794(45.3)$ & $1934(44.9)$ \\
\hline *Others & $2(0.1)$ & $5(0.3)$ & $7(0.1)$ \\
\hline \multicolumn{4}{|l|}{ Ethnicity } \\
\hline Mandinka & $862(33.7)$ & $617(35.3)$ & $1479(34.3)$ \\
\hline Fula & $656(25.7)$ & $398(22.7)$ & $1054(24.5)$ \\
\hline Wolof & $392(15.3)$ & $216(12.3)$ & $608(14.1)$ \\
\hline Jola & $143(5.6)$ & $264(15.1)$ & $407(9.4)$ \\
\hline Serahule & $343(13.4)$ & $40(2.3)$ & $383(8.9)$ \\
\hline${ }^{+}$Others & $162(6.3)$ & $215(12.3)$ & $377(8.8)$ \\
\hline
\end{tabular}

*The others are retirees

+ The Others include Aku, Serere, Manjago, Jahanka 
Table 2 TB knowledge of the respondents stratified by area of residence

\begin{tabular}{|c|c|c|c|c|c|}
\hline Variable & $\begin{array}{l}\text { Rural residence } \\
(N=2558)\end{array}$ & $\begin{array}{l}\text { Urban residence } \\
(N=1751)\end{array}$ & $\begin{array}{l}\text { Difference in } \\
\text { proportions }\end{array}$ & $\begin{array}{l}\text { Total } \\
(N=4309)\end{array}$ & \\
\hline & $\mathrm{N}(\%)$ & $\mathrm{N}(\%)$ & $\%(95 \% \mathrm{Cl})$ & $\mathrm{N}(\%)$ & $P$ value \\
\hline *Have you heard about TB? & $2199(86.0)$ & $1418(81.0)$ & $5(2.7,7.3)$ & 3617 (83.9) & $<0.001$ \\
\hline \multicolumn{6}{|l|}{${ }^{*}$ How serious the respondent regarded TB } \\
\hline Life threatening & 2059 (80.5) & $1386(79.2)$ & $1.3(-1.1,3.8)$ & $3445(80.0)$ & 0.281 \\
\hline Not very serious/threatening & $224(8.8)$ & $209(12.0)$ & $-3.1(-5.1,-1.3)$ & $433(10.0)$ & 0.001 \\
\hline Don't know & $275(10.8)$ & $156(8.9)$ & $1.8(0.1,3.6)$ & $431(10.0)$ & 0.048 \\
\hline \multicolumn{6}{|l|}{${ }^{*}$ Common TB symptoms and signs } \\
\hline Cough that lasts for $2-3$ weeks & $1840(71.9)$ & $1303(74.4)$ & $-2.5(-5.2,0.2)$ & $3143(72.9)$ & 0.072 \\
\hline Bloody sputum & $1597(62.4)$ & $1142(65.2)$ & $-2.8(-5.7,0.1)$ & $2739(63.6)$ & 0.062 \\
\hline Weight loss & $1686(65.9)$ & $1197(68.4)$ & $-2.5(-5.3,0.4)$ & $2883(67.0)$ & 0.093 \\
\hline Fever & $1541(60.2)$ & $1021(58.3)$ & $1.9(-1.1,4.9)$ & $2562(59.5)$ & 0.204 \\
\hline Chest pain & $1674(65.4)$ & $1169(66.8)$ & $-1.3(-4.2,1.6)$ & $2843(66.0)$ & 0.369 \\
\hline Shortness of breath & $1571(61.4)$ & $1085(62.0)$ & $-0.6(-3.5,2.4)$ & $2656(61.6)$ & 0.716 \\
\hline \multicolumn{6}{|l|}{${ }^{*}$ Mode of TB transmission } \\
\hline Through air when a person with TB cough or sneezes & $1864(72.9)$ & $1357(77.5)$ & $-4.6(-7.2,-2.0)$ & $3221(74.8)$ & 0.001 \\
\hline By living with a TB patient & $1149(44.9)$ & $834(47.6)$ & $-2.7(-5.7,0.3)$ & $1983(46.0)$ & 0.079 \\
\hline By sharing dishes, plates, cups and spoons & $1830(71.5)$ & $1256(71.7)$ & $-0.2(-2.9,2.5)$ & $3086(71.6)$ & 0.892 \\
\hline Through smoking cigarettes or drinking alcohol & $1472(57.5)$ & $972(55.5)$ & $2.0(-0.1,0.05)$ & $2444(56.7)$ & 0.186 \\
\hline \multicolumn{6}{|l|}{ *Mode of prevention } \\
\hline Covering mouth and nose when coughing or sneezing & $1795(70.2)$ & $1300(74.2)$ & $-4.0(-6.8,-1.4)$ & $3095(71.8)$ & 0.004 \\
\hline Avoid sharing dishes, spoons and cups & $1794(70.1)$ & $1253(71.6)$ & $-1.4(-4.2,1.3)$ & $3047(70.7)$ & 0.312 \\
\hline Avoiding people who appear to have TB & $1104(43.1)$ & $713(40.7)$ & $2.4(-0.6,5.4)$ & $1817(42.2)$ & 0.111 \\
\hline Through good nutrition & $1059(41.4)$ & $613(35.0)$ & $6.4(3.5,9.3)$ & $1672(38.8)$ & $<0.001$ \\
\hline By praying and fasting & $971(38.0)$ & $511(29.2)$ & $8.8(5.9,11.6)$ & $1482(34.4)$ & $<0.001$ \\
\hline Avoid handshakes & $364(14.2)$ & $238(13.6)$ & $0.6(-1.5,2.7)$ & $602(14.0)$ & 0.553 \\
\hline \multicolumn{6}{|l|}{ Can TB be cured? } \\
\hline Yes & $2203(86.1)$ & $1607(91.8)$ & $-5.7(-7.5,-3.8)$ & $3810(88.4)$ & $<0.001$ \\
\hline No & $43(1.7)$ & $12(0.7)$ & $1.0(0.4,1.6)$ & $55(1.3)$ & 0.004 \\
\hline Don't know & $312(12.2)$ & $132(7.5)$ & $4.7(2.9,6.4)$ & $444(10.3)$ & $<0.001$ \\
\hline \multicolumn{6}{|c|}{ *How can someone with TB be cured? (Rural $N=2203$, Urban $N=1607$, Total $N=3810$ ) } \\
\hline Drugs specifically for TB & $2132(96.8)$ & $1550(96.5)$ & $0.3(-0.8,1.5)$ & $3682(96.6)$ & 0.583 \\
\hline Herbal remedies & $225(10.2)$ & $161(10.0)$ & $0.2(-1.7,2.1)$ & $386(10.1)$ & 0.844 \\
\hline Praying and fasting & $77(3.5)$ & $60(3.7)$ & $-0.2(-1.4,1.0)$ & $137(3.6)$ & 0.696 \\
\hline Good nutrition & $30(1.4)$ & $18(1.1)$ & $0.2(-0.5,0.9)$ & $40(1.3)$ & 0.509 \\
\hline \multicolumn{6}{|l|}{ Cost of TB treatment in the country? } \\
\hline It is free & $932(36.4)$ & $782(44.7)$ & $-8.2(-11.2,-5.2)$ & $1714(39.8)$ & $<0.001$ \\
\hline Pay some fee & $458(17.9)$ & $241(13.8)$ & $4.1(1.9,6.3)$ & $699(16.2)$ & $<0.001$ \\
\hline Don't know & $1168(45.7)$ & $728(41.6)$ & $4.1(1.1,7.1)$ & $1896(44.0)$ & 0.008 \\
\hline \multicolumn{6}{|l|}{ Overall TB Knowledge } \\
\hline Poor & $882(34.5)$ & $544(31.1)$ & $3.4(0.6,6.3)$ & $1426(33.1)$ & 0.019 \\
\hline Good & $1676(65.5)$ & $1207(68.9)$ & $-3.4(-6.3,-0.6)$ & $2883(66.9)$ & 0.019 \\
\hline
\end{tabular}

"Only the "Yes" responses tabulated 


\section{Sample size}

The TB prevalence survey (GAMSTEP) had a very large sample size of 55, 281. The target sample size for the KAP survey was $10 \%$ of all GAMSTEP participants and was chosen due to feasilibility, practicability and giving the unknown prevalence of the outcomes of interest. Thus, assuming $50 \%$ prevalence, the $10 \%$ of 55,281 would provide a $>80 \%$ power for a statistical meaningful deduction.

\section{Statistical analysis}

Descriptive data were summarised and presented as frequencies and percentages (proportions). We tabulated categorical responses in proportions and assessed for associations with residence using the Pearson Chi-square test and assessed for differences in proportions using tests of equality of proportions. Associations between participant characteristics and each of the 3 outcome variables (TB knowledge, attitude and practice) were explored in univariable logistic regression analyses. A multivariable logistic regression analysis was performed including all the independent variables that showed significant association at a $5 \%$ level in the univariable analysis. We used a randomeffects logistic regression model to account for clustering in the multistage sampling used for the parent study. Due to the exploratory nature of the analysis, no adjustment was made for multiple testing. There was $<1 \%$ missing data which was not corrected for as this did not alter the result.

\section{Ethical approval}

This study was approved by the Joint Ethics Committee of the Gambian Government and Medical Research
Council Unit, The Gambia, as part of the national TB survey. Written informed consent was obtained from all participants.

\section{Results}

Demographic characteristics

A total of 4309 of 43,100 participants in the main survey were interviewed. The mean age of the study population was 32.5 years (interquartile range, IQR 20-65 years). As shown in Table 1, the majority of our study population were females (59.2\%), married (60.7\%), unemployed (55\%) and resided in rural areas (59.4\%). A significant proportion of the population were illiterate (43\%), and of Mandinka ethnicity (34.3\%).

The study population mean scores (standard deviations) for knowledge, attitude and practice towards $\mathrm{TB}$ are $8( \pm 4), 3( \pm 0.9)$ and $1.8( \pm 0.5)$ respectively.

\section{Knowledge about TB}

Overall, most participants indicated they had heard about TB (Table 2), however TB awareness was 5\% (95\% CI: 2.7-7.3) higher in rural compared to urban residents and this was significantly different $(p<0.001)$.

TB was considered a very serious or life-threatening condition by similar numbers of urban and rural dwellers. The 3 correct TB symptoms most commonly given by participants were long-lasting cough (72.9\%), weight loss $(67 \%)$ and chest pain $(66 \%)$ and these responses did not differ by area of residence (see Table 2).

Overall, about three-quarters of participants correctly identified the airborne route as the mode of $\mathrm{TB}$

Table 3 Source participants first heard about TB based on residence, gender and age grouping

\begin{tabular}{|c|c|c|c|c|c|}
\hline Variable & N (\%) & $\mathrm{N}(\%)$ & $\%(95 \% \mathrm{Cl})$ & N (\%) & $P$ value \\
\hline Residence & Rural $(N=2199)$ & Urban $(N=1418)$ & Difference in proportions & Total $(N=3617)$ & \\
\hline Family, friends and neighbours & $864(39.3)$ & $560(39.5)$ & $-0.2(-3.5,3.1)$ & $1424(39.4)$ & 0.22 \\
\hline Radio & $917(41.7)$ & $460(32.4)$ & $9.3(6.1,12.5)$ & $1377(38.0)$ & $<0.001$ \\
\hline TV & $159(7.2)$ & $260(18.3)$ & $-11.1(-13.4,-8.8)$ & $419(11.6)$ & $<0.001$ \\
\hline${ }^{*}$ Others & $259(11.8)$ & $138(9.7)$ & $2.1(-0.0,4.1)$ & $397(11.0)$ & 0.06 \\
\hline Gender & Female $(N=2168)$ & Male $(N=1449)$ & Difference in proportions & Total $(\mathrm{N}=3617)$ & \\
\hline Family, friends and neighbours & $823(38.0)$ & $601(41.5)$ & $-3.5(-6.8,-0.3)$ & $1424(39.4)$ & 0.03 \\
\hline Radio & $831(38.3)$ & $546(37.7)$ & $0.6(-2.6,3.9)$ & $1377(38.0)$ & 0.69 \\
\hline TV & $261(12.0)$ & $158(10.9)$ & $1.1(-1.0,3.2)$ & $419(11.6)$ & 0.30 \\
\hline${ }^{*}$ Others & $253(11.7)$ & $144(9.9)$ & $1.8(-0.3,3.8)$ & $397(11.0)$ & 0.10 \\
\hline Age grouping & $15-34$ years $(N=2237)$ & $\geq 35$ years $(N=1380)$ & Difference in proportions & Total $(\mathrm{N}=3617)$ & \\
\hline Family, friends and neighbours & $874(39.1)$ & $550(39.9)$ & $-0.8(-4.1,2.5)$ & $1424(39.4)$ & 0.64 \\
\hline Radio & $808(36.1)$ & $569(41.2)$ & $-5.1(-8.4,-1.8)$ & $1377(38.0)$ & 0.002 \\
\hline TV & $299(13.4)$ & $120(8.7)$ & $4.7(2.6,6.7)$ & $419(11.6)$ & $<0.001$ \\
\hline${ }^{*}$ Others & $256(11.4)$ & $141(10.2)$ & $1.2(-0.8,3.3)$ & $397(11.0)$ & 0.25 \\
\hline
\end{tabular}

*This include teachers, health workers, print media, religious leaders 
transmission. Although significantly more urban than rural residents correctly associated TB transmission with the airborne route, similar proportions of rural and urban-based participants also erroneously attributed a role to sharing cutlery and crockery in TB transmission (Table 2). With respect to preventing TB transmission, $\sim 72 \%$ overall, and significantly more urban than ruralbased participants correctly identified covering the mouth or nose during coughs and sneezes as useful for preventing TB transmission (Table 2). However, over $40 \%$ of all participants considered avoiding those perceived as having TB as a means of preventing transmission and this response did not vary by residence. Furthermore, over a third of all participants and predominantly more rural dwellers identified roles for good nutrition and religion (through praying and fasting) in the prevention of TB.

The majority (88.4\%) of the participants understood TB was curable with a significant urban preponderance. Out of this proportion, almost everyone (96.6\%) had the understanding that it can be cured by taking drugs specifically for TB while a minor proportion said herbal remedies, praying and fasting, and good nutrition are ways of TB treatment. Compared to the understanding that TB can be cured, about $40 \%$ of participants and mainly urban dwellers were aware TB treatment was free in the country (Table 2).

Among those who had knowledge of TB (Table 3), similar proportions of rural and urban resident participants first heard about TB from family, friends,

Table 4 Factors associated with good knowledge among the respondents

\begin{tabular}{|c|c|c|c|c|c|c|}
\hline \multirow[t]{2}{*}{ Variable $(n=4309)$} & \multicolumn{3}{|c|}{ Unadjusted } & \multicolumn{3}{|c|}{ Adjusted for all the variables } \\
\hline & OR & $95 \% \mathrm{Cl}$ & $P$-value & OR & $95 \% \mathrm{Cl}$ & $P$-value \\
\hline \multicolumn{7}{|l|}{ Sex } \\
\hline Female $^{+}$ & 1.00 & & & 1.00 & & \\
\hline Male & 1.33 & $1.15-1.53$ & $<0.001$ & 1.04 & $0.86-1.26$ & 0.687 \\
\hline \multicolumn{7}{|l|}{ Age group } \\
\hline $15-34$ yrs. $^{+}$ & 1.00 & & & 1.00 & & \\
\hline $35-64$ yrs & 1.42 & $1.21-1.65$ & $<0.001$ & 1.40 & $1.15-1.69$ & 0.001 \\
\hline$\geq 65 \mathrm{yrs}$ & 1.04 & $0.76-1.43$ & 0.806 & 1.19 & $0.83-1.71$ & 0.337 \\
\hline \multicolumn{7}{|l|}{ Marital status } \\
\hline Single $^{+}$ & 1.00 & & & 1.00 & & \\
\hline married & 1.38 & $1.19-1.60$ & 0.001 & 1.54 & $1.27-1.88$ & $<0.001$ \\
\hline Once married* & 0.97 & $0.68-1.37$ & 0.858 & 1.31 & $0.86-1.98$ & 0.210 \\
\hline \multicolumn{7}{|l|}{ Educational status } \\
\hline illiterate $^{+}$ & 1.00 & & & 1.00 & & \\
\hline Read English/Arabic & 1.25 & $1.02-1.51$ & 0.027 & 1.35 & $1.08-1.67$ & 0.007 \\
\hline Primary/Incomplete Sec. school & 1.46 & $1.20-1.76$ & $<0.001$ & 1.97 & $1.57-2.46$ & $<0.001$ \\
\hline Secondary school \& above & 2.70 & $2.14-3.41$ & $<0.001$ & 3.67 & $2.79-4.84$ & $<0.001$ \\
\hline \multicolumn{7}{|l|}{ Employment status } \\
\hline unemployed $^{+}$ & 1.00 & & & 1.00 & & \\
\hline Employed & 1.59 & $1.37-1.84$ & $<0.001$ & 1.42 & $1.19-1.70$ & $<0.001$ \\
\hline \multicolumn{7}{|l|}{ Residence } \\
\hline Rural $^{+}$ & 1.00 & & & 1.00 & & \\
\hline Urban & 1.21 & $0.76-1.91$ & 0.421 & 0.95 & $0.53-1.71$ & 0.874 \\
\hline \multicolumn{7}{|l|}{ Attitude towards TB } \\
\hline Unfavorable ${ }^{+}$ & 1.00 & & & 1.00 & & \\
\hline Favourable & 2.66 & $2.21-3.20$ & $<0.001$ & 2.30 & $1.90-2.78$ & $<0.001$ \\
\hline \multicolumn{7}{|l|}{ Practice towards TB } \\
\hline Poor $^{+}$ & 1.00 & & & 1.00 & & \\
\hline Good & 2.38 & $1.87-3.03$ & $<0.001$ & 2.03 & $1.58-2.60$ & $<0.001$ \\
\hline
\end{tabular}

${ }^{+}$This is the reference category

*This comprises of widow(er) and separated/divorced 
neighbours and colleagues. In contrast to urban areas where television was an important source of TB awareness, the radio played a bigger role in rural communities. A significantly higher proportion of participants in the older age category i.e. $\geq 35$ years acquired their TB knowledge from the radio compared to younger participants (15 to 34 year). As expected for the younger age category (15-34 years), TV was a more important source of TB knowledge than for their older counterparts (Table 3).

\section{Overall knowledge}

Given their scores, two-thirds of all participants had overall good knowledge of TB and urban residents significantly had more knowledge than their rural counterparts (see Table 2).

We assessed a range of exposures for associations with overall TB knowledge as shown in Table 4. After controlling for other variables in the model, age $(35-64$ yrs), marital status, education, being employed, a favourable attitude towards TB and good practice with respect to $\mathrm{TB}$ were all predictors of good $\mathrm{TB}$ knowledge.
With education, there was a dose-response relationship as the biggest effect was seen with education to secondary level and above. There was no evidence interaction between residence and age or educational status nor between marital status and age or educational status or residence (data not shown).

\section{Attitudes and practice towards TB}

As shown in Table 5, just over half of all participants thought they could get TB and significantly more urban dwellers recognised this possibility than the rural ones. With respect to their range of feelings if diagnosed with $\mathrm{TB}$, majority of rural compared to urban residents identified with negative feelings of fear, surprise, shame, embarrassment, sadness and hopelessness. Over threequarters of participants also indicated they would be happy if diagnosed with TB because the underlying cause of their ill-health would have been identified and can be treated. However, this view was held by predominantly more urban participants compared to the rural (see Table 5).

Table $\mathbf{5}$ TB attitudes of respondents stratified by area of residence

\begin{tabular}{|c|c|c|c|c|c|}
\hline \multirow[t]{2}{*}{ Variable } & \multirow{2}{*}{$\begin{array}{l}\text { Rural residence } \\
(N=2558) \\
N(\%)\end{array}$} & \multirow{2}{*}{$\begin{array}{l}\text { Urban Residence } \\
(N=1751) \\
N(\%)\end{array}$} & \multirow{2}{*}{$\begin{array}{l}\text { Difference in } \\
\text { proportions } \\
\%(95 \% \mathrm{Cl}) \\
\end{array}$} & \multirow{2}{*}{$\begin{array}{l}\text { Total } \\
(N=4309) \\
N(\%) \\
\end{array}$} & \multirow[t]{2}{*}{$p$-value } \\
\hline & & & & & \\
\hline *Do you think you can get TB? & $1370(53.6)$ & $1103(63.0)$ & $-9.4(-12.4,-6.5)$ & $2473(57.4)$ & $<0.001$ \\
\hline \multicolumn{6}{|c|}{ *How would you feel if you were found to have TB? } \\
\hline Fear & $1549(60.6)$ & $868(49.6)$ & $11.0(8.0,14.0)$ & $2417(56.1)$ & $<0.001$ \\
\hline Surprise & $1700(66.5)$ & $1015(58.0)$ & $8.5(5.5,11.4)$ & $2715(63.0)$ & $<0.001$ \\
\hline Shame & $851(33.3)$ & $440(25.1)$ & $8.1(5.4,10.9)$ & $1291(30.0)$ & $<0.001$ \\
\hline Embarrassment & $842(32.9)$ & $441(25.2)$ & $7.7(5.0,10.5)$ & $1283(29.8)$ & $<0.001$ \\
\hline Sadness & $1651(64.5)$ & $1017(58.1)$ & $6.5(3.5,9.4)$ & $2668(61.9)$ & $<0.001$ \\
\hline Hopelessness & $649(25.4)$ & $384(21.9)$ & $3.4(0.9,6.0)$ & $1033(24.0)$ & 0.009 \\
\hline Happiness & $1903(74.4)$ & $1383(79.0)$ & $-4.6(-7.1,-2.0)$ & $3286(76.3)$ & 0.001 \\
\hline \multicolumn{6}{|c|}{ *Who would you talk to about your illness if you had TB? } \\
\hline Health workers & $2440(95.4)$ & $1667(95.2)$ & $0.2(-1.1,1.5)$ & 4107 (95.3) & 0.779 \\
\hline Spouse & $2343(91.6)$ & $1562(89.2)$ & $2.4(0.6,4.2)$ & 3905 (90.6) & 0.008 \\
\hline Parents & $2329(91.0)$ & $1572(89.8)$ & $1.3(-0.5,3.1)$ & $3901(90.5)$ & 0.162 \\
\hline Children & $2234(87.3)$ & $1465(83.7)$ & $3.7(1.5,5.8)$ & 3699 (85.8) & 0.001 \\
\hline Landlord/Household head & $2230(87.2)$ & $1426(81.4)$ & $5.7(3.5,8.0)$ & $3656(84.9)$ & $<0.001$ \\
\hline Close friend & $2032(79.4)$ & $1368(78.1)$ & $1.3(-1.2,3.8)$ & $3400(78.9)$ & 0.300 \\
\hline \multicolumn{6}{|l|}{ How do you feel about people with TB? } \\
\hline I try to help & $1233(48.2)$ & $948(54.1)$ & $-5.9(-9.0,-2.9)$ & $2181(50.6)$ & $<0.001$ \\
\hline I stay away from them & $1186(46.4)$ & $710(40.6)$ & $5.8(2.8,8.8)$ & $1896(44.0)$ & $<0.001$ \\
\hline Treat them like I treat other people & $139(5.4)$ & $93(5.3)$ & $0.1(-1.2,1.5)$ & $232(5.4)$ & 0.861 \\
\hline \multicolumn{6}{|l|}{ Overall attitude } \\
\hline Unfavourable & $2040(79.7)$ & $1280(73.1)$ & $6.6(4.1,9.2)$ & $3320(77.0)$ & $<0.001$ \\
\hline favourable & $518(20.3)$ & $471(26.9)$ & $-6.6(-9.2,-4.1)$ & $989(23.0)$ & $<0.001$ \\
\hline
\end{tabular}

*Only the "Yes" responses tabulated 
In addition to speaking to their relations, household head and close friends following a diagnosis of TB, majority of participants and similar numbers by residence indicated willingness to speak to health workers. While many more rural than urban participants indicated they would speak to spouse, children and household heads about their diagnosis, fewer urban participants were likely to discuss their diagnosis with their landlord or household head. When asked about how they feel about persons with $\mathrm{TB}$, a little under half of all participants expressed a preference for staying away from them rather than providing support. As shown in Table 5, this preference for withdrawing from TB patients was expressed in more rural than urban residents.

There was near universal preference for visiting a health centre among participants if they felt they had TB symptoms and indication of good health seeking behaviour although with a slight but significant urban preponderance. Most $(84.2 \%)$ of the participants reported that they would go immediately if they develop TB symptoms. There was no significant difference by sex in the participant's preference for visiting a health centre (data not shown). In addition, inhabitants of rural parts of the country were more likely to consider self-treatment and consult traditional healers and religious leaders as indicated in Table 6.

\section{Overall attitude and practice}

Most participants in this survey had an unfavourable attitude towards TB and this attitude was exhibited mostly by rural residents. In the multivariable analyses, favourable attitude towards TB was associated with being male, married, having at least primary level education, being employed, having good TB knowledge and good practice towards TB (Table 7). However, the underlying attitude was different if participants were directly affected by TB. The majority of participants had good practice regarding TB if they were personally affected, and this was significantly more in urban compared to rural residents. The key predictors of good practice for TB were being married, having at least primary school level education, having a job, good TB knowledge and favourable attitude towards TB (Table 8).

\section{Discussion}

From 2010 to 2019, there were 16 nationwide TB prevalence surveys in African countries including The Gambia [1]. However, only Gambia of all these countries seems to have also conducted a TB knowledge, attitudes and practice concurrently. By studying a nationally representative population in the context of a nationwide TB prevalence survey, we were able to investigate the knowledge, attitude and practice with respect to $\mathrm{TB}$ on a national level for the first time in The Gambia.

Of the $80 \%$ of our population who had some knowledge of $\mathrm{TB}$, only two-thirds had good or appropriate knowledge, and a significantly higher proportion of them were urban residents. Good TB knowledge in The Gambia was associated with age, marital status, education, employment, a good TB attitude and practice. These findings are consistent with those from other studies despite our lower prevalence of participants with appropriate knowledge [30-35].

We observed a discordance between responses regarding the mode of TB transmission. On one hand, majority of the participants correctly identified the airborne route as the means by which TB is transmitted but up to twothirds also believe TB transmission was still possible if

Table 6 TB practice of respondents stratified by area of residence

\begin{tabular}{|c|c|c|c|c|c|}
\hline \multicolumn{6}{|c|}{ *What would you do if you had TB symptoms? } \\
\hline Go to the health facility & $2440(95.4)$ & $1717(98.1)$ & $-2.7(-3.7,-1.6)$ & $4157(96.5)$ & $<0.001$ \\
\hline Go to pharmacy & $167(6.5)$ & $110(6.3)$ & $0.2(-1.2,1.7)$ & $277(6.4)$ & 0.746 \\
\hline Go to traditional healer & $305(11.9)$ & $116(6.6)$ & $5.3(3.6,7.0)$ & $421(9.8)$ & $<0.001$ \\
\hline Go to religious leader & $83(3.2)$ & $29(1.7)$ & $1.6(0.7,2.5)$ & $112(2.6)$ & 0.001 \\
\hline Pursue self-treatment & $88(3.4)$ & $30(1.7)$ & $1.7(0.8,2.7)$ & $118(2.7)$ & 0.001 \\
\hline \multicolumn{6}{|c|}{ At what point will you go to the health facility if you develop TB symptoms? } \\
\hline Will go immediately & $2092(81.8)$ & $1535(87.7)$ & $-5.9(-8.0,-3.7)$ & $3627(84.2)$ & $<0.001$ \\
\hline Will not go at all & $102(4.0)$ & $24(1.4)$ & $2.6(1.7,3.6)$ & $126(2.9)$ & $<0.001$ \\
\hline${ }^{* *}$ Others & $364(14.2)$ & $192(11.0)$ & $3.3(1.3,5.3)$ & $556(12.9)$ & 0.002 \\
\hline \multicolumn{6}{|l|}{ Overall practice } \\
\hline Poor & $477(18.6)$ & $225(12.8)$ & $5.8(3.6,8.0)$ & $702(16.3)$ & $<0.001$ \\
\hline Good & $2081(81.4)$ & $1526(87.2)$ & $-5.8(-8.0,-3.6)$ & 3607 (83.7) & $<0.001$ \\
\hline
\end{tabular}

*Only the "Yes" responses tabulated

**if symptoms don't get worse/when self-treatment fails/wait for 3 to 4 weeks 
Table 7 Factors associated with favourable attitudes among the respondents

\begin{tabular}{|c|c|c|c|c|c|c|}
\hline \multirow[t]{2}{*}{ Variable $(n=4309)$} & \multicolumn{3}{|c|}{ Unadjusted } & \multicolumn{3}{|c|}{ Adjusted for all the variables } \\
\hline & $\overline{\mathrm{OR}}$ & $95 \% \mathrm{Cl}$ & $\overline{P \text {-value }}$ & $\overline{\mathrm{OR}}$ & $95 \% \mathrm{Cl}$ & $P$-value \\
\hline \multicolumn{7}{|l|}{ Sex } \\
\hline Female $^{+}$ & 1.00 & & & 1.00 & & \\
\hline Male & 1.45 & $1.24-1.70$ & $<0.001$ & 1.25 & $1.03-1.53$ & 0.028 \\
\hline \multicolumn{7}{|l|}{ Age group } \\
\hline $15-34$ yrs. $^{+}$ & 1.00 & & & 1.00 & & \\
\hline $35-64 y r s$ & 1.34 & $1.13-1.58$ & 0.001 & 1.12 & $0.91-1.37$ & 0.296 \\
\hline$\geq 65$ yrs & 1.14 & $0.79-1.64$ & 0.479 & 1.23 & $0.82-1.85$ & 0.311 \\
\hline \multicolumn{7}{|l|}{ Marital status } \\
\hline Single $^{+}$ & 1.00 & & & 1.00 & & \\
\hline Married & 1.51 & $1.28-1.79$ & $<0.001$ & 1.67 & $1.34-2.07$ & $<0.001$ \\
\hline Once married & 0.74 & $0.48-1.16$ & 0.193 & 0.94 & $0.56-1.55$ & 0.799 \\
\hline \multicolumn{7}{|l|}{ Educational status } \\
\hline Illiterate $^{+}$ & 1.00 & & & 1.00 & & \\
\hline Primary/Incomplete Sec. school & 1.21 & $0.98-1.51$ & 0.075 & 1.39 & $1.09-1.77$ & 0.008 \\
\hline Read English/Arabic & 1.19 & $0.96-1.49$ & 0.114 & 1.09 & $0.86-1.39$ & 0.475 \\
\hline Sec. school \& above & 2.01 & $1.61-2.52$ & $<0.001$ & 2.04 & $1.57-2.65$ & $<0.001$ \\
\hline \multicolumn{7}{|l|}{ Employment status } \\
\hline Unemployed $^{+}$ & 1.00 & & & 1.00 & & \\
\hline Employed & 1.66 & $1.42-1.95$ & $<0.001$ & 1.30 & $1.07-1.57$ & 0.008 \\
\hline \multicolumn{7}{|l|}{ Residence } \\
\hline Rural $^{+}$ & 1.00 & & & 1.00 & & \\
\hline Urban & 1.63 & $1.00-2.66$ & 0.049 & 1.48 & $0.87-2.50$ & 0.144 \\
\hline \multicolumn{7}{|l|}{ Knowledge of TB } \\
\hline Poor $^{+}$ & 1.00 & & & 1.00 & & \\
\hline Good & 2.65 & $2.20-3.19$ & $<0.001$ & 2.21 & $1.83-2.68$ & $<0.001$ \\
\hline \multicolumn{7}{|l|}{ Practice towards TB } \\
\hline Poor $^{+}$ & 1.00 & & & 1.00 & & \\
\hline Good & 3.27 & $2.33-4.59$ & $<0.001$ & 2.80 & $1.97-3.97$ & $<0.001$ \\
\hline
\end{tabular}

${ }^{+}$This is the reference category

cutlery and crockery are shared with persons with $\mathrm{TB}$, and that avoiding this was a means of TB prevention. This suggests that while ACSM and other interventions might have introduced the population to the concept of airborne transmission for $\mathrm{TB}$, more work is required to change their core beliefs and practice regarding TB transmission. Given the wider access to radio in ours and other similar settings, [36, 37] it was not surprising to find radio was the main source of TB knowledge in rural areas while TV played a bigger role in urban areas in The Gambia. However, it was not a common source of TB information as observed in other studies [15, 38]. Similar to our study, others [34] have also found that communities acquire TB knowledge from their family, friends, and colleagues. These suggest contextualised interventions via the radio and/or community-based may be an effective way in reaching out to a lot of people to improve and consolidate their TB knowledge. There was no association between TB knowledge and sex as reported by other investigators [15, 36], however, some other studies have reported an association [14, 33, 35, 39].

We found a population with a predominantly negative attitude to TB including high levels of stigmatising behaviour, especially in rural residents which may contribute to the gaps in TB detection and treatment seen in The Gambia and other African TB prevalence surveys. It is our experience from $\mathrm{TB}$ case-contact research in urban Gambia [40] that newly diagnosed TB patients are frequently isolated in their households. In addition, they were often allocated their own kitchen utensils within their households. This practice is no doubt the 
Table 8 Factors associated with good practice among the respondents

\begin{tabular}{|c|c|c|c|c|c|c|}
\hline \multirow[t]{2}{*}{ Variable $(n=4309)$} & \multicolumn{3}{|c|}{ Unadjusted } & \multicolumn{3}{|c|}{ Adjusted for all the variables } \\
\hline & OR & $95 \% \mathrm{Cl}$ & $P$-value & OR & $95 \% \mathrm{Cl}$ & $P$-value \\
\hline \multicolumn{7}{|l|}{ Sex } \\
\hline Female $^{+}$ & 1.00 & & & - & & \\
\hline Male & 0.99 & $0.82-1.19$ & 0.900 & - & - & - \\
\hline \multicolumn{7}{|l|}{ Age group } \\
\hline $15-34$ yrs. $^{+}$ & 1.00 & & & - & & \\
\hline $35-64 y r s$ & 1.07 & $0.87-1.31$ & 0.518 & - & - & - \\
\hline$\geq 65$ yrs & 0.83 & $0.56-1.23$ & 0.358 & - & - & - \\
\hline \multicolumn{7}{|l|}{ Marital status } \\
\hline Unmarried $^{+}$ & 1.00 & & & 1.00 & & \\
\hline Married & 1.30 & $1.06-1.59$ & 0.013 & 1.63 & $1.28-2.08$ & $<0.001$ \\
\hline Once married & 0.92 & $0.60-1.41$ & 0.716 & 1.34 & $0.84-2.13$ & 0.220 \\
\hline \multicolumn{7}{|l|}{ Educational status } \\
\hline Illiterate ${ }^{+}$ & 1.00 & & & 1.00 & & \\
\hline Primary/Incomplete Sec. school & 1.52 & $1.18-1.94$ & 0.001 & 1.82 & $1.37-2.42$ & $<0.001$ \\
\hline Read English/Arabic & 1.16 & $0.88-1.51$ & 0.292 & 1.17 & $0.88-1.56$ & 0.282 \\
\hline Sec. school \& above & 4.05 & $2.70-6.05$ & $<0.001$ & 4.08 & $2.65-6.23$ & $<0.001$ \\
\hline \multicolumn{7}{|l|}{ Employment status } \\
\hline Unemployed $^{+}$ & 1.00 & & & 1.00 & & \\
\hline Employed & 1.38 & $1.13-1.68$ & 0.001 & 1.25 & $1.01-1.54$ & 0.039 \\
\hline \multicolumn{7}{|l|}{ Residence } \\
\hline Rural $^{+}$ & 1.00 & & & - & & \\
\hline Urban & 1.93 & $0.78-4.76$ & 0.152 & - & - & - \\
\hline \multicolumn{7}{|l|}{ Knowledge of TB } \\
\hline Poor $^{+}$ & 1.00 & & & 1.00 & & \\
\hline Good & 2.62 & $2.05-3.34$ & $<0.001$ & 2.08 & $1.62-2.67$ & $<0.001$ \\
\hline \multicolumn{7}{|l|}{ Attitude towards TB } \\
\hline Unfavorable ${ }^{+}$ & 1.00 & & & 1.00 & & \\
\hline Favourable & 3.09 & $2.19-4.36$ & $<0.001$ & 2.26 & $1.58-3.23$ & $<0.001$ \\
\hline
\end{tabular}

'This is the reference category

consequence of erroneous belief that TB transmission is possible if cutlery and crockery are shared with persons with TB and contributes to the level of stigmatisation observed in this study. Furthermore, this stigma is also fuelled by the negative attitudes of fear, avoidance, surprise, shame and sadness that participants indicated they would feel if ever diagnosed with TB. When considered alongside the poor TB knowledge exhibited by 3 out of 10 persons in The Gambia especially in rural areas, this is a considerable challenge that needs to be tackled head on as part of TB control efforts [41, 42] especially in a country with mostly rural dwelling population [26]. Male sex, marriage, at least primary education, employment, a good knowledge and practice of $\mathrm{TB}$ were predictive of more favourable attitudes to TB. However, the association of male sex with a positive attitude towards TB is unexpected given the Gambian TB prevalence survey [3] just like others [4, 43, 44] and in concordance with global TB epidemiology shows majority of TB cases are males [1]. This may be closely related to their health-seeking behaviour when they have TB-like symptoms [9].

Most of our participants had good health seeking behaviour or practice regarding TB. In contrast, most of the $\mathrm{TB}$ cases in the prevalence survey were previously undiagnosed in the community and were not on treatment [3]. This disparity between health seeking behaviour and case detection in the community underlies the importance of ensuring health centres are adequately equipped, and health workers are adequately trained to, facilitate early diagnosis and treatment of TB. These will 
help prevent missed opportunities for TB diagnosis and reduce the spread of $\mathrm{TB}$ and possibly associated stigma $[1,18,38,44,45]$. It is possible that reported healthseeking behaviours might be different from actual actions which may also explain the discordance between a favourable attitude to $\mathrm{TB}$ and the preponderance of undiagnosed male $\mathrm{TB}$ cases during the $\mathrm{TB}$ prevalence survey in Gambia and elsewhere.

The general predictors of good knowledge, attitude and health-seeking behaviour regarding TB in our study are being married, having some form of education and being employed. This was also observed by Luba et al. [33] while other studies [13-15] also found similar relationships with education and employment status. The participants in this study who were married were more likely to be in the older (35-64 years) age group that had a very good knowledge of TB and good TB knowledge was significantly associated with favourable attitude and good health-seeking behaviour towards TB. However, we did not find any interaction between marital status and age or educational status in our final model. This suggests that improvement in TB awareness campaign activities irrespective of educational background of a population is important for TB control efforts [31, 32, 35, 46].

Our large sample size and a nationally representative population are main strengths of this study. Given the cross-sectional design, our inference regarding the directionality of the 'predictors' of good knowledge, attitude and practice is somewhat limited and requires further investigation. Beyond the factors explored here that are co-determinants of health-seeking behaviour, factors directly related to health care system also contribute to delays in TB diagnosis and treatment but these were not the focus of this study. Nonetheless, well informed communities in addition to identification of other structural contributors to delays in seeking TB care have been identified as important for TB control [20, 21, 47-49]. Our study provides valuable insights regarding societal knowledge of TB, exposes the significant stigma in the community and identifies some areas requiring intervention by the national TB programme and other stakeholders in the fight to control TB in The Gambia and similar settings.

\section{Conclusions}

In conclusion, whilst the majority of participants had good health-seeking practice, there was still significant stigma associated with TB as well as knowledge gaps on transmission, prevention and cost of treatment of TB. Focused community-based campaigns to educate people on $\mathrm{TB}$ are required as part of community engagement for TB control in the NLTP's ACSM strategy. In addition, the use of radio and television tailored to deliver TB education to rural and urban dwellers should complement the community engagement strategies for a wider reach. Training and continued re-training of health care workers especially community and village health workers to educate the public on TB at every opportunity they get are also critical to all of the efforts outlined above.

\section{Supplementary information}

Supplementary information accompanies this paper at https://doi.org/10. 1186/s12889-020-09685-3.

Additional file 1. Questionnaire for TB KAP Study - contains 29 questions used for the survey about TB knowledge, attitude and careseeking behaviour as well as their source of information regarding TB.

\section{Abbreviations}

ACSM: Advocacy, Communication and Social Mobilization; GAMS TEP: Gambian Survey of Tuberculosis Prevalence; KAP: Knowledge, Attitude and Practice; MRCG: Medical Research Council Unit, The Gambia; NLTP: National Leprosy and Tuberculosis Progamme; TB: Pulmonary Tuberculosis

\section{Acknowledgements}

We would like to thank all the participants in the study for taking part in the study and the NLTP team for their support throughout the study. Also grateful to Dr. Ikechukwu Adigweme and Dr. Muyiwa Owolabi for guidance in the early phase of the draft report, both of the MRCG at LSHTM.

\section{Authors' contributions}

$\mathrm{AB}$ contributed to the conduct of the study, data analysis and data interpretation and wrote the initial draft of this study report. $C L$ and SO contributed to the conduct of the study and review of the draft report. LK contributed in the statistical analysis of this study, SD oversaw the data entry and responsible for cleaning and management of the database. MK, BD, LL, and SK contributed to the conduct of the study. UDA contributed to the design and implementation of the study and interpretation of its results. IA was the lead for the study design, oversaw the study implementation, and substantively revised the draft study report. All authors have read through the manuscript and approved it for submission for publication.

\section{Funding}

The Global Fund to Fight AIDS, Tuberculosis and Malaria financed this study through grant GMB-MRC-T with support from the MRCG. The funders were not involved in the design, conduct, analysis and publication of this study. The corresponding author had full access to the study data and was responsible for the decision to submit for publication.

\section{Availability of data and materials}

The data that supports the findings in this study can be made available through contacting the corresponding author under reasonable request and with permission from the director of The Medical Research Council Unit, the Gambia (MRCG)

\section{Ethics approval and consent to participate}

The main study (GAMSTEP) was approved by the Joint Ethics Committee of the Gambian Government and Medical Research Council Unit The Gambia. Written informed consent was obtained from all participants before they took part in the study. For participants less than 18 years, the parent or guardian provided written consent on their behalf. Whereas participants 18 years and above provided written consent for themselves.

\section{Consent for publication}

Not applicable.

\section{Competing interests}

The authors declare that they have no competing interests. 


\section{Author details}

'Disease Control and Elimination Theme, Medical Research Council Unit The Gambia at London School of Hygiene and Tropical Medicine, P.O. Box 273, Banjul, The Gambia. ${ }^{2}$ Department of Infectious Diseases Epidemiology, London School of Hygiene and Tropical Medicine, London, UK.

Received: 15 April 2020 Accepted: 13 October 2020

Published online: 17 October 2020

\section{References}

1. World Health Organization. Global Tuberculosis Report. Geneva, Switzerland: World Health Organization; 2019.

2. Wondawek TM, Ali MM. Delay in treatment seeking and associated factors among suspected pulmonary tuberculosis patients in public health facilities of Adama town, eastern Ethiopia. BMC Public Health. 2019;19(1):1527.

3. Adetifa IM, Kendall L, Bashorun A, Linda C, Omoleke S, Jeffries D, et al. A tuberculosis nationwide prevalence survey in Gambia, 2012. Bull World Health Organ. 2016;94(6):433-41.

4. Kebede AH, Alebachew Z, Tsegaye F, Lemma E, Abebe A, Agonafir M, et al. The first population-based national tuberculosis prevalence survey in Ethiopia, 2010-2011. Int J Tuberc Lung Dis. 2014;18(6):635-9.

5. Department of Public Health Federal Republic of Nigeria. Report of the first national TB prevalence survey 2012, Nigeria. 2014.

6. Rwanda Biomedical Center Ministry of Health. Report of the first national pulmonary tuberculosis prevalence survey in Rwanda (2012). 2014.

7. Senkoro M, Mfinanga S, Egwaga S, Mtandu R, Kamara DV, Basra D, et al. Prevalence of pulmonary tuberculosis in adult population of Tanzania: a national survey, 2012. Int J Tuberc Lung Dis. 2016;20(8):1014-21.

8. Ministry of Health National TB Control Programme. Technical report: Malawi tuberculosis prevalence survey (2013-2014). 2016.

9. Kapata N, Chanda-Kapata P, Ngosa W, Metitiri M, Klinkenberg E, Kalisvaart N, et al. The Prevalence of Tuberculosis in Zambia: Results from the First National TB Prevalence Survey, 2013-2014. PloS One. 2016;11(1):e0146392-e.

10. Ministry of Health and Child Care. The Zimbabwe National Population based Tuberculosis Prevalence Survey. 2014

11. Subbaraman R, Jhaveri T, Nathavitharana RR. Closing gaps in the tuberculosis care cascade: an action-oriented research agenda. J Clin Tuberc Other Mycobact Dis. 2020;19:100144.

12. Sultan H, Haroon S, Syed N. Delay and completion of tuberculosis treatment: a cross-sectional study in the west midlands, UK. J Public Health. 2012;35(1):12-20.

13. Adane K, Spigt M, Johanna L, Noortje D, Abera SF, Dinant GJ. Tuberculosis knowledge, attitudes, and practices among northern Ethiopian prisoners: implications for TB control efforts. PLoS One. 2017;12(3):e0174692.

14. Abebe G, Deribew A, Apers L, Woldemichael K, Shiffa J, Tesfaye M, et al. Knowledge, health seeking behavior and perceived stigma towards tuberculosis among tuberculosis suspects in a rural community in Southwest Ethiopia. PLoS One. 2010;5(10):e13339.

15. Tolossa D, Medhin G, Legesse M. Community knowledge, attitude, and practices towards tuberculosis in Shinile town, Somali regional state, eastern Ethiopia: a cross-sectional study. BMC Public Health. 2014;14:804.

16. Eastwood S, Hill P. A gender-focused qualitative study of barriers to accessing tuberculosis treatment in the Gambia, West Africa. Int J Tuberc Lung Dis. 2004;8(1):70-5.

17. Paul S, Akter R, Aftab A, Khan AM, Barua M, Islam S, et al. Knowledge and attitude of key community members towards tuberculosis: mixed method study from BRAC TB control areas in Bangladesh. BMC Public Health. 2015;15:52.

18. Storla DG, Yimer S, Bjune GA. A systematic review of delay in the diagnosis and treatment of tuberculosis. BMC Public Health. 2008;8:15.

19. Kasa AS, Minibel A, Bantie GM. Knowledge, attitude and preventive practice towards tuberculosis among clients visiting public health facilities. BMC Res Notes. 2019;12(1):276.

20. Lienhardt C, Rowley J, Manneh K, Lahai G, Needham D, Milligan P, et al. Factors affecting time delay to treatment in a tuberculosis control programme in a sub-Saharan African country: the experience of the Gambia. Int J Tuberc Lung Dis. 2001;5(3):233-9.

21. Getnet F, Demissie M, Assefa N, Mengistie B, Worku A. Delay in diagnosis of pulmonary tuberculosis in low-and middle-income settings: systematic review and meta-analysis. BMC Pulm Med. 2017;17(1):202.
22. Yang YR, McManus DP, Gray DJ, Wang XL, Yang SK, Ross AG, et al. Evaluation of the tuberculosis programme in Ningxia Hui autonomous region, the People's republic of China: a retrospective case study. BMC Public Health. 2012;12(1):1110.

23. Asres A, Jerene D, Deressa W. Delays to anti-tuberculosis treatment intiation among cases on directly observed treatment short course in districts of southwestern Ethiopia: a cross sectional study. BMC Infect Dis. 2019;19(1):481.

24. Ministry of Health and Social Welfare. Strategic Plan for Tuberculosis Control 2013-2017. Gambia; 2014.

25. Ministry of Health and Social Welfare. National Health Policy 2012-2020. Banjul: The Gambia; 2012.

26. Gambia Bureau of Statistics. The Gambia 2013 Population and housing census preliminary results. The Gambia; 2013.

27. The World Bank. The World Bank In The Gambia 2018 [cited 27 Feb 2018] Available from: http://www.worldbank.org/en/country/gambia/overview\#4.

28. Harper M, Ahmadu FA, Ogden JA, McAdam KP, Lienhardt C. Identifying the determinants of tuberculosis control in resource-poor countries: insights from a qualitative study in the Gambia. Trans R Soc Trop Med Hyg. 2003; 97(5):506-10.

29. World Health Organization. Tuberculosis prevalence survey: a handbook. Geneva, Switzerland 2011.

30. Noé A, Ribeiro RM, Anselmo R, Maixenchs M, Sitole L, Munguambe K, et al. Knowledge, attitudes and practices regarding tuberculosis care among health workers in Southern Mozambique. BMC Pulm Med. 2017;17(1):2.

31. Balogun MR, Sekoni AO, Meloni ST, Odukoya OO, Onajole AT, Longe-Peters $\mathrm{OA}$, et al. Predictors of tuberculosis knowledge, attitudes and practices in urban slums in Nigeria: a cross-sectional study. Pan Afr Med J. 2019;32:60.

32. Balogun M, Sekoni A, Meloni ST, Odukoya O, Onajole A, Longe-Peters O, et al. Trained community volunteers improve tuberculosis knowledge and attitudes among adults in a periurban community in Southwest Nigeria. Am J Trop Med Hyg. 2015;92(3):625-32.

33. Luba TR, Tang S, Liu Q, Gebremedhin SA, Kisasi MD, Feng Z. Knowledge, attitude and associated factors towards tuberculosis in Lesotho: a population based study. BMC Infect Dis. 2019;19(1):96.

34. Pengpid S, Peltzer K. Knowledge, attitudes, and practices regarding tuberculosis in Timor-Leste: results from the demographic and health survey 2016. J Prev Med Public Health. 2019;52(2):115-22.

35. Hassan AO, Olukolade R, Ogbuji QC, Afolabi S, Okwuonye LC, Kusimo OC, et al. Knowledge about tuberculosis: a precursor to effective TB controlfindings from a follow-up national KAP study on tuberculosis among Nigerians. Tuberc Res Treat 2017;2017:6309092.

36. Kwedi Nolna S, Kammogne ID, Ndzinga R, Afanda B, Ntone R, Boum Y, et al. Community knowledge, attitudes and practices in relation to tuberculosis in Cameroon. Int J Tuberc Lung Dis. 2016;20(9):1199-204.

37. Fana TE, ljeoma E, Sotana L. Knowledge, attitudes, and prevention practices of drug resistant tuberculosis in the eastern Cape Province, South Africa. Tuberc Res Treat. 2019;2019:8978021.

38. Kasse $Y$, Jasseh $M$, Corrah $T$, Donkor SA, Antonnio M, Jallow $A$, et al. Health seeking behaviour, health system experience and tuberculosis case finding in Gambians with cough. BMC Public Health. 2006;6:143.

39. Bati J, Legesse M, Medhin G. Community's knowledge, attitudes and practices about tuberculosis in Itang special district, Gambella region, South Western Ethiopia. BMC Public Health. 2013;13:734.

40. Hill PC, Ota MO. Tuberculosis case-contact research in endemic tropical settings: design, conduct, and relevance to other infectious diseases. Lancet Infect Dis. 2010;10(10):723-32.

41. Amo-Adjei J, Kumi-Kyereme A. Myths and misconceptions about tuberculosis transmission in Ghana. BMC Int Health Hum Rights. 2013;13:38.

42. Daftary A, Frick M, Venkatesan N, Pai M. Fighting TB stigma: we need to apply lessons learnt from HIV activism. BMJ Glob Health. 2017;2(4):e000515.

43. Onozaki I, Law I, Sismanidis C, Zignol M, Glaziou P, Floyd K. National tuberculosis prevalence surveys in Asia, 1990-2012: an overview of results and lessons learned. Trop Med Int Health. 2015;20(9):1128-45.

44. Bonsu F, Addo KK, Alebachew Z, Gyapong J, Badu-Peprah A, Gockah R, et al. National population-based tuberculosis prevalence survey in Ghana, 2013. Int J Tuberc Lung Dis. 2020;24(3):321-8.

45. Bogale S, Diro E, Shiferaw AM, Yenit MK. Factors associated with the length of delay with tuberculosis diagnosis and treatment among adult tuberculosis patients attending at public health facilities in Gondar town, northwest, Ethiopia. BMC Infect Dis. 2017;17(1):145. 
46. Bisallah Cl, Rampal L, Lye MS, Mohd Sidik S, Ibrahim N, lliyasu Z, et al.

Effectiveness of health education intervention in improving knowledge, attitude, and practices regarding tuberculosis among HIV patients in general hospital Minna, Nigeria - a randomized control trial. PLoS One. 2018; 13(2):e0192276.

47. World Health Organization. The End TB Strategy 2018 [cited 22 Oct 2018]. Available from: http://www.who.int/tb/post2015_TBstrategy.pdf?ua=1.

48. World Health Organization. Advocacy, communication, \& social mobilization (ACSM) for tuberculosis control. Geneva, Switzerland: World Health Organization; 2007.

49. Adenager GS, Alemseged F, Asefa H, Gebremedhin AT. Factors associated with treatment delay among pulmonary tuberculosis patients in public and private health facilities in Addis Ababa, Ethiopia. Tuberc Res Treat 2017;2017: 5120841.

\section{Publisher's Note}

Springer Nature remains neutral with regard to jurisdictional claims in published maps and institutional affiliations.

- fast, convenient online submission

- thorough peer review by experienced researchers in your field

- rapid publication on acceptance

- support for research data, including large and complex data types

- gold Open Access which fosters wider collaboration and increased citations

- maximum visibility for your research: over $100 \mathrm{M}$ website views per year

At $\mathrm{BMC}$, research is always in progress. 